\title{
Psychosocial support conditions in the orphanage: case study of Wolisso project
}

\author{
Getachew Abeshu Disassa ${ }^{1 *}$ (D) and Dabala Lamessa ${ }^{2}$
}

\section{${ }^{*}$ Correspondence:}

gbona2003@yahoo.com

${ }^{1}$ Department of Psychology,

Jimma University, Jimma,

Ethiopia

Full list of author information

is available at the end of the

article

\begin{abstract}
This study was conducted to assess the psychosocial and material services provision of Wolisso Kalehiwot Church project/center. Qualitative research design employing phenomenological approach was conducted as to reach on identifying the strengths and challenges practiced in the center. Purposive sampling techniques was used to draw ten respondents from the center (8 from orphans, 2 from staff) to respond to interview questions. The result of this study indicated that the effort made by the project is so effective in addressing the immediate need of the orphans including survival and wellbeing of these children. Consequently, the weakness in the project observed was initial recruitment problem of the orphans and unskilled staffs involving in the project and the inability to be proactive for the sustainability request for the project were seen as major. The challenges faced were identified as characteristics of the staff to handle the growing needs of the orphans, emotional instability of the children, limited access to social integration, negative attitude of the community towards institutionalization and segregation were observed as critical. Hence, institutional capacity building from both external and internal funders to maintain the projects sustainability with clear goal and policy direction is mandatory.
\end{abstract}

Keywords: Double orphan, Institution, Orphanage, Psycho-social support, Single orphan

\section{Introduction}

Today the concept of orphan is creating some degree of confusion with regard to defining who is an orphan; how many are there; what are their characteristics; where are they found; what are the trends in orphan hood; and most importantly, what are the specific needs of orphans as distinct from other children in their communities.

Myovela indicated that orphans in industrialized countries are referred as a child who has lost both parents. However, in the context of the AIDS pandemic, orphan is defined as those who have lost both parents (double orphan) but also those who have lost a father but have a surviving mother or have lost their mother but have a surviving father (single orphan).By this definition there were over 132 million orphans in sub Saharan Africa, Asia, Latin America and the Caribbean in 2005. Sub-Saharan Africa is home to 12.3 million orphans and the number has increased rapidly in a short few years to a 
point in which the entire African continent appears to be overwhelmed by the "orphan crisis" Myovela (2012).

In addition, other study also indicated that, definition on "orphans" have caused some confusion, because most international organizations have used the term to refer to children who have lost one or both parents, but many people understand the term to refer to children with no parents, and the reality is that the vast majority of orphaned and vulnerable children worldwide are being care for by their surviving parents and extended family members, not in orphanages. For example, in Zimbabwe, which has had one of the highest HIV rates in the world, a UNICEF study found that over 98 percent of children who have lost one or both parents are living with families (UNICEF, 2009).

According to UNICEF (2010), the definition of an orphan for statistical purposes is that a child under 18 years who has lost one or both parents. A single orphan is a child who has lost one parent; a double orphan is a child who lost both parents. A maternal orphan is a child whose mother died, while a paternal orphan has lost the father. Crises such as disease or famine that affect children increase the rate of growth of orphans in the population. For statistical purposes, children are no longer considered orphans after they reach 18 years of age. Therefore, the number of orphans in a population group increases if the number of children losing their parents exceeds the number of orphans turning 18 , causing the percentage of orphans in that population to rise also.

As of the updated evidence by UNICEF in 2012, UNICEF and numerous international organizations adopted the broader definition of orphan in the mid-1990s as the AIDS pandemic began leading to the death of millions of parents worldwide, leaving an ever increasing number of children growing up without one or more parents. Therefore, the terminology of a 'single orphan'-the loss of one parent-and a 'double orphan' - the loss of both parents-was born to convey this growing crisis. However, this difference in terminology can have concrete implications for policies and programming for children. For example, UNICEF's 'orphan' statistic might be interpreted to mean that globally there are 132 million children in need of a new family, shelter, or care. This misunderstanding may then lead to responses that focus on providing care for individual children rather than supporting the families and communities that care for orphans and are in need of support.

As Global facts about orphanages prepared by: Better Care Network Secretariat, updated August, 2009 shown, poverty, seek for education access, disability, minority in ethnics, violence within the family are the common factors for children to be admitted into the orphanages in addition to loss of their parents due to leading cause of death, AIDS (Powel, 2004).

Although HIV/AIDS has reached almost every part of the world, no other region has been harder hit than sub-Saharan Africa, home to nearly three quarters of the world's people living with HIV/AIDS. The figures for Africa shown that in the benchmark years of 1990 the percentage of children orphaned in sub-Saharan African countries as a result of AIDS rose sharply from (1\%) to (7\%) 1995, (17\%) in 2000 and $25 \%$ in 2005, and is projected to reach $30 \%$ of all orphans by 2010 . Among them are over 10 million children who have lost both parents. AIDS is the leading cause of death among adults ages 15-59, and it has produced 12 million orphans in the region. The rates of HIV deaths are not uniform across Sub-Saharan Africa, but are much higher in southern Africa, where as 
many as $15 \%$ of all children are orphans. Behind these figures is a tremendous toll of human suffering. Older children may act as caregivers for their parents or siblings who are ill, or grandparents may have to raise their grandchildren. Furthermore, poor nutrition, inability to attend school, inability to concentrate, emotional trauma and depression are among the most serious effects, and children whose families have been touched by AIDS may also be stigmatized by others, further worsening these effects (Thurman et al., 2007).

In connection with the mental health, children who are deprived of the parental care and a secure family environment often become vulnerable to a host of psychological problems and psychiatric disorders. Since these children are then usually reared in institutional homes set up by the government or private agencies, which provide some semblance of order into their lives, they feel discomfort of missing something. In these homes also, the problems of overcrowding, inadequate personal attention, poor academic environment, and frequent moves may affect the psychological health of these children (Kaur et al., 2018).

In a certain situation, then a residential childcare facility that is intended to care for children from the time of their admission until their maturity and which holds comprehensive professional treatment services for children to address their emotional, behavioral, or other problems is preferable. This is way different authorized childcare centers including wolisso kalehiwot church; orphans rehabilitation center are providing the care services. Based on this premise, the researcher intended to visit and assess the basic needs and psychosocial supports this rehabilitation center providing and the challenges encountered.

\section{Statement of the problem}

Children are one part of population group and as a population group, it has no doubt that they are increasingly major victims of the consequences of becoming destitute and orphans as parents lose their lives to AIDS and other factors. This may also put Orphaned children at disadvantaged in numerous and often devastating ways. One of the major impacts of being orphaned is lack of access and possibility of involving in schooling. Chityo et al. (2016) as cited from Gunderson, Kelly, and Jemison (2004) indicated that Children orphaned by HIV/AIDS may miss out on school, have their schooling disrupted, or perform poorly in school. They farther narrated that a number of issues affect the children's school attendance. First, children may have to take care of their sick parents and perform household chores, and often drop out of school to meet these responsibilities. Second, limited financial resources mean it is difficult to pay school fees or buy school uniforms and textbooks. Some children may be forced to drop out of school so they can work to generate income to sustain the household. Zeenat et al. (2018) further described HIV-related stigma inhibited the psychosocial functioning and well-being of children orphaned by AIDS.

It is common knowledge that the HIV/AIDS prevalence rate differ in different continents and regions within same continents. Among these different continents, the prevalence rate is high in sub-Saharan countries including Ethiopia in the world. According to the 2011 EDHS, HIV prevalence is $1.9 \%$ for women and $1.0 \%$ for men with an overall prevalence of $1.5 \%$. This is essentially unchanged from the HIV prevalence reported 
in 2005 (1.4\%). HIV prevalence is six and a half times higher among women living in urban areas (5.2\%) than among women living in rural areas (0.8\%). HIV estimates vary by age, with HIV prevalence highest among women age 30-34 and men age 35-39. HIV prevalence also varies by region, ranging from a low of $0.9 \%$ in SNNPR to $6.5 \%$ in Gambela. HIV prevalence is highest among employed women and men and those living in the wealthiest households (Ethiopia Demographic and Health Survey (EDHS, 2011). According to UNICEF, Ethiopia, the second-most populous nation in Africa with about 102 million people, has one of the largest orphan populations in the world. Nearly 13 percent of the children live without one or both parents (UNICEF, 2018 report).

As of UNICEF (2010) for instance, in addition to the trauma of witnessing the sickness and death of one or both parents, children are likely to be poorer and less healthy than non-orphans are and they are more likely to suffer damage to their cognitive and emotional development, less likely to go to school, more likely to be subjected to the worst forms of child labor.

The social and emotional effects of this diseases are numerous and profound. When a parent dies of AIDS, his or her child is three times more likely to die-even when that child is HIV negative. Besides, facing an increased risk of death, children whose parents have died due to HIV/AIDS also confront stigmatization, rejection and a lack of love and care. They often suffer from emotional distress, malnutrition, a lack of health care, and poor or no access to education. They are also at high risk for labor exploitation, sex trafficking, homelessness, and exposure to HIV. Increasingly, extended families and communities in highly affected areas find that their resources are inadequate to provide the basics for all needy children. In communities hard hit by the double hammer of HIV/ AIDS and poverty, there are millions of children who may be orphans, or who have been made more vulnerable by HIV/AIDS (PEPFAR, 2006).

As a result many children left alone and being orphaned especially in respect to countries those more affected by this disease. For instance, the proportion of orphans defined as children who have lost one or both parents is greatest in Sub-Saharan Africa, with 12.3 million orphans. By 2015, the epidemic is expected to peak, and orphans will make up $9 \%$ to $12 \%$ of the total population in the sub-Saharan Africa, this data suggest a population rate of double orphans of 2.1\% in sub-Saharan Africa (Myovela, 2012).

Therefore, it shows that HIV/AIDS is very complex issue that put children at risk of being left alone and this needs provision of different comprehensive orphans care in institution and out of institution. In this regard the contribution of different organizations including religious institution is very great to reduce the spread of HIV/AIDS and caring for orphaned. That is why different rehabilitation centers are needed to care for children who lost their parents whether both or one parents.

However, different general problems can be associated with institutional care. For example, as stated by Tsegaye Chernet (2001), many problems were challenged orphan institutions such as; inadequate funding to support programs designed for the children, shortage of trained personnel, inadequate skills training that resulted in long care in orphanages, lack of psychosocial services, and lack of long-term strategic planning. As a result of these and other problems, the children in the orphanages often elicit unwanted behavior; such as: feelings of loneliness and hopelessness, dependency on the adult population for all their needs, low self-esteem and feeling of inferiority and etc. 
As different research finding also indicates, the key issues and observations in Children recruited into institutions are that: institution recruit in line with a 'vision' rather than the needs of the community; most children in the institutions assessed have families and sometimes visited them; poor child record keeping, policies and procedures are very limited; caregivers are often ill-equipped and unskilled to deliver quality child care services; social work efforts were not taken seriously in most institutions; limited awareness of the legal requirements to Children's Act or home regulations, and limited 'formal' engagement between different officials and institutions.

Thus here, the researchers intended to visit Wolisso Kalehiwot Church; orphans rehabilitation center/project and the holistic activities/services given within and out of this rehabilitation center regarding the orphans.

At the end of the study, the researcher is highly concerned to answer the following basic research questions:

- What are the mission, vision, and core values of the rehabilitation center in relation to the orphanage care and services?

- What procedures are in use to conduct need assessment, monitoring and evaluation in the rehabilitation center?

- What are the services basically this institution providing?

- What are the major problematic issues in this center in relation to service provision for orphans?

\section{Objective of the study}

The general objective of the study is to find out the holistic activities of this rehabilitation center along with its provision of services for orphans in line with regional context.

Along with this general objective, the following are specific objectives of this study:

- To identify the employment of activities stated in the vision, mission and core values of the center

- To examine the procedures in use during needs assessment, monitoring and evaluation

- To assess the services provision and activities effectiveness in the institution in supporting emotional and personal needs of the children

- To explore challenges faced and prospects related to the institution/center.

\section{Delimitation of the study}

This study was conducted in Oromia Region, South West Shewa Zone, Wolisso Town on wolisso Kalehiwot Church orphans rehabilitation center/project. The researchers intended to study basically the overall activities performed in the center in view of rehabilitation counseling. 


\section{Significance of this study}

This study is so imperative; because, once problems are investigated, the findings of the research are beneficial for all the members of this center as to understand the nature of the problem and find helpful solution with professional support. The findings may also help the project coordinator, social workers/counselor, childcare givers and the orphaned themselves in general in and out of the institution by extending similar experiences to others. This study also can give an insight on the major problems under consideration with problem classification leading to analogous elucidation. In addition, the results of the study can be used as a foundation tip for further investigation on the orphan's problems.

\section{Operational definition of terms}

Child: Person under the age of 18.

Orphan: The definition in this instance is a child who has lost one or both of his/her parent (s).

Vulnerable children: In the context of HIV/AIDS, vulnerability refers to children living in a household where the duty bearer and bread winner is ill AIDS or died of it. It also refers to children living in a household that takes in orphaned children.

Double orphans: child who has lost both of his/her parent (s).

Single orphans: child who has lost one of his/her parent (s).

Neglected orphans: child who ignored by his/her parent (s).

Care-giver: the individual, usually the mother, but in this study, social workers, care providers and other facilitators who takes responsibility for the physical, mental and emotional needs and well-being of a child in the orphanage.

\section{Research methods}

Design of the study: Brink (2009) described research design as the set of logical steps taken by the researcher to answer the research questions. It forms the 'blue print' of the study and determines the methodology used by the researcher to obtain sources of information. Polit and Beck (2008) as cited by Sendagala (2010), defined research design as the overall plan for addressing a research question, including specifications for enhancing the study's integrity. Hence a qualitative research paradigm which is explorative, descriptive and contextual was used to explore and describe the issues related to orphans in the rehabilitation center.

Based on the aforementioned statements, the researcher used the phenomenological approach of the qualitative paradigm. Phenomenology is defined as a science whose purpose is to describe particular phenomena or the appearance of things, as lived experiences (Streubert \& Carpenter, 2007). Burns and Grove (2009) also state that the purpose of phenomenological research is to describe and capture the experiences as they are lived. It is this lived experience that gives meaning to each individual's perception of a particular phenomenon and is influenced by everything internal and external to the individual.

Population: The research had been conducted in Wolisso Town on Wolisso Kalehiwot Church, orphans rehabilitation center. Wolisso is one of the moderate towns of 
South Western Oromia Regional State found around $115 \mathrm{~km}$ away from the metropoli$\tan$. To conduct a research on all orphans, appear difficult and even complex, since their involvement and responding with intended age limit are discretionary. For this reason, a researcher attempted to consider key informants and able to respond population group in the center with limited number of orphans. Adolescents of the center in grade eight were nineteen in number presumed as able bodied to react to interview questions were selected from this population.

Sample and sampling techniques: Purposive sampling technique is a type of nonprobability sampling where the researcher consciously selected particular elements or subjects so as to make sure that the elements will have certain characteristics pertinent to the study. It normally targets particular group of people. It is a technique also called judgment sampling with deliberate choice of an informant due to the qualities the informant possesses. It is a nonrandom technique that does not need underlying theories or a set number of informants. Simply put, the researcher decides what needs to be known and sets out to find people who can and are willing to provide the information by virtue of knowledge or experience (Bernard, 2002; Lewis \& Shepard 2006). Based on this suggestion, the researcher purposively selected a total of ten (10) participants. From these, 2 project facilitators and 8 orphans of the project/rehabilitation were included in the study.

Instrument: An interview guide was used to collect data. The participants were asked about their experiences regarding the rehabilitation center, service providing and assessment, monitoring and evaluation systems they are employing. In addition, observation of the participants/orphans also used to assess their emotional and behavioral feeling using observation checklist prepared by a researcher and commented by advisor. Finally, document accessible on the topic of the orphans and the rehabilitation center were used.

Procedures of data collection: Data collection is defined as the precise, systematic gathering of information relevant to the research purpose or the specific objectives and questions of a study (Burns \& Grove, 2009) as cited by Susan Rugari (2012). The researcher initially communicated church administration and manager/coordinator of the project. After securing acceptance, the researchers determined number of facilitators involved in the interview. The identified ten respondents were communicated and appointments for participation were set. Finally, participants were interviewed based on their consent and observation was conducted at the orphanage center accordingly.

Methods of data analysis: The researcher employed qualitative method of study involving narrative data analysis techniques which was specifically description of statements (describing responses of participants in words through categorizing into different categories, and use of percentage, and tabulation of respondent's biography). Respondents' interview documents were put for final reference until manuscript will be published.

Ethical considerations: The following ethical deliberations have been emphasized throughout this study. Accordingly, the researcher followed a standard and scientific procedure of doing research in such a very sensitive topic. Accordingly, the subjects and study population were introduced first about the purpose of the study, keeping confidentiality of the information gathered from them. Then informed consent from respondents and relevant officials of the institutions covered in the study was obtained to discuss 
with and interview them. The participants were also informed that they have full right to discontinue or refuse to participate in the study.

\section{Results and discussion}

In this chapter the researcher has discussed the research findings, which include the setting location, vision, mission, values, orphans demographic characteristics, assessment mechanisms, services the center executing, presence of counseling service, monitoring and evaluation mechanisms, demographic data of the participants and themes that emerged from data analysis.

\section{The geographical location of the center}

Wolisso Kalehiwot Church, orphans project/rehabilitation center is the newly established center before 12 years and located in Wolisso Town, the capital of South West Shewa Zone, Oromia Regional State. It began services by providing basic needs services such as food, water, shelter, clothing etc. for orphans including other social services such as health and educational supports. $85 \%$ of the institutions fund is originated from external body donor, world orphans chair foundation, USA and 15\% is generated from internal source, specifically by the church itself. This center has one project coordinator, two chefs, two caregivers and one cleaner.

In general, under vision, mission and core values, though they did not state in written form, verbally they expressed the following issues during interview time.

Vision-To witness that children of both sexes equally enjoy their basic needs, meet their needs spiritually, physically, academically and emotionally preparing them for a brighter future, so that they become good citizens with outstanding personality.

Mission-Their mission is to love, care; create hope and better aspirations for orphans and vulnerable children. The view is comparatively similar globally.

\section{Governing values}

- We alleviate the suffering of children.

- We restore and demonstrate dignity and respect for orphaned and vulnerable children.

- We follow the biblical directive and standards to love and care for orphans.

- We prevent the exploitation of the vulnerable, abandoned, neglected, rejected and suffering child.

- We develop and maintain an approach to rescuing and caring for orphaned children that meets their needs spiritually, physically, academically and emotionally (Table 1).

As the above table indicates, the majorities $52.6 \%$ (10) of the orphans are male followed by $47.4 \%$ (9) female orphans children. The ages of these orphans ranges from the minimum 6 to the maximum 14. In the same table, the majority $42.1 \%$ (8) referred to different grade levels of the orphans where as $26.3 \%$ (equal numbers referred to KG-2 and KG-3) educational level followed by the least 5.3\% KG-1 level orphans. Finally, the same table shown that the highest $68.42 \%$ (13) are double orphans followed by $21.05 \%$ (4) neglected orphans with the least $10.53 \%$ (2) single types of orphans. 
Table 1 Demographic results of orphans

\begin{tabular}{|c|c|c|c|}
\hline $\mathrm{S} / \mathrm{N}$ & Category & Frequency & Percent \\
\hline \multirow[t]{3}{*}{1} & \multirow[t]{3}{*}{ Sex } & $M=10$ & 52.6 \\
\hline & & $F=9$ & 49 \\
\hline & & Total $=19$ & 100 \\
\hline 2 & Ages & Range from 6 to 14 & - \\
\hline \multirow[t]{5}{*}{3} & \multirow[t]{5}{*}{ Educational levels } & $K G-1=1$ & 5.3 \\
\hline & & $K G-2=5$ & 26.3 \\
\hline & & $K G-3=5$ & 26.3 \\
\hline & & Grades $=8$ & 42.1 \\
\hline & & Total $=19$ & 100 \\
\hline \multirow[t]{10}{*}{4} & \multirow{3}{*}{$\begin{array}{l}\text { Types of orphans } \\
\text { Double orphans }\end{array}$} & $M=7$ & \\
\hline & & $F=6$ & \\
\hline & & Total $=13$ & 68.42 \\
\hline & \multirow[t]{3}{*}{ Single orphans/without father } & $M=2$ & \\
\hline & & $F=-$ & \\
\hline & & Total $=2$ & 10.53 \\
\hline & \multirow[t]{4}{*}{ Neglected orphans } & $M=1$ & \\
\hline & & $F=3$ & \\
\hline & & Total $=4$ & 21.05 \\
\hline & & Grand total & 100 \\
\hline
\end{tabular}

Source: by researchers

Needs assessment mechanisms-The interview result indicated that orphans needs assessment mechanism employed during screening was not appropriate to address all children (orphaned) to be included in the institution. Formal selection procedures were not employed directly by the professionals, but the authority was gave the decision for 12 woreda children and women affair offices of South Western Zones experts being with woreda finance and economic development office to bring orphan children they identified during their work with children under their offices. The institution hoped that the woreda/district children and women affair office basically work with children and presumed that these offices easily identify orphaned children in their catchments.

Participants' demographic data-This study involved a total of ten (10) participants. From these, two (2) were working as project facilitators in the center, while eight (8) of them were orphans from Wolisso Kalehiwot Church, orphan project/rehabilitation center. The participant ages ranged between 26 and 34 for facilitators and $6-14$ for orphans. The study gave attention to gender mix where almost equivalent numbers of gender involved to provide information. Children participated in the study were from grade eight only, since they are appropriate to give consent and reliable information compared to the KG ones.

Presence of rehabilitation counseling services-Respondents underlined that except for advice, discussion and guiding services all activities are provided by nonprofessional workers; no professional rehabilitation counselor or social worker provide counseling services for these orphans in general. The entire workers in the center are engaged on activities related to educational, material and basic needs provision than focusing on emotional and psychological support for the orphan in the institution/center. 
Withregard to mechanisms of monitoring and evaluation, one of the respondents indicated that monthly report, supervision of the committee statement, supervision narrations of external body such as funding body and other governmental bodies are the mechanisms they employ to monitor and evaluate their work performances.

\section{Analysis regarding problems of service delivery}

Four main themes were emerged from data analysis of this center coordinators responses. These are:

1) Characteristics of caregivers in the institution

2) Characteristics of orphans in the institution

3) Needs assessment, monitoring of the centers progress and evaluation of their performance, comprising statement of institutional vision, mission and core values.

4) Capacity related to work related problems (Table 2).

As of the result from interview conducted with the two people, coordinator of the project and administrator of the church indicates, a researcher identified four themes as indicated in the table above. The major issues under each themes crop up different conditions as teething troubles. Accordingly, characteristics of caregivers in the institution, characteristics of orphans themselves in the institution, inefficient

Table 2 Themes and lists of categories regarding the service delivery from the facilitator's/ coordinators point of view

\begin{tabular}{|c|c|c|}
\hline $\mathrm{S} / \mathrm{N}$ & The main themes & Lists of categories under each main themes \\
\hline 1 & Characteristics of caregiver in the institution & $\begin{array}{l}\text { Lack of skills in caring motherly and fatherly } \\
\text { Lack of commitment } \\
\text { Devaluing their job due to less salary they earned } \\
\text { Loss of interest to care orphans as needed } \\
\text { Poor at satisfying emotional interest of orphans }\end{array}$ \\
\hline 2 & $\begin{array}{l}\text { Characteristics of orphans themselves in the institu- } \\
\text { tion }\end{array}$ & $\begin{array}{l}\text { Age difference } \\
\text { Lack of interaction and sometimes they seem to feel } \\
\text { unhappy } \\
\text { Easily annoyed } \\
\text { Feel sad for being there for long time } \\
\text { Gradual feeling about loss of their parents } \\
\text { Question of 'why we stay here' by those who lost their } \\
\text { parents at early stage } \\
\text { Health related problems and hygiene }\end{array}$ \\
\hline 3 & $\begin{array}{l}\text { Unseemly needs assessment, monitoring the pro- } \\
\text { gress and evaluation of their performance }\end{array}$ & $\begin{array}{l}\text { The needs assessment tools and procedures lack } \\
\text { technical qualities; i.e., they rely on external reports of } \\
\text { woreda/district offices, where the objective and goal } \\
\text { are so different } \\
\text { Poor in recording their daily activities and displaying } \\
\text { their data in figure } \\
\text { No or very limited document stating their journey } \\
\text { which enables them to monitor and evaluate their } \\
\text { performance systematically }\end{array}$ \\
\hline 4 & Capacity related service performances & $\begin{array}{l}\text { Absence of professional counselor/social worker in } \\
\text { the rehabilitation/project center } \\
\text { Financial shortages to recruit sufficient workers (pro- } \\
\text { fessionals) and fulfill relevant materials } \\
\text { Lack of enough funds from internal and external } \\
\text { bodies other than interested groups abroad and the } \\
\text { church }\end{array}$ \\
\hline
\end{tabular}

Source: Organization chart 
needs assessment, monitoring the progress and evaluation of their performance and capacity related problems are the main themes. The respondents retorted that the leading causes of being orphaned are the epidemic of HIV/AIDS, followed by neglect from some family members due to confounding factors like poor economic capability to assist the children, instability of family structure, number of children in the family and early loss of parents before children become able to support themselves. Project workers identified that there is lack of appropriate professional or expert in rehabilitation counseling as to assist children in the orphanage project where most of the children needs emotional comfort to ease loss of one or both parents at this age. During its establishment, the project of orphan children didn't rely on clear needs assessment tools of screening and identifying to select the orphaned children where many children lost access of involving in the rehabilitation project due to the distance of their home, lack of information and supporting agents from government offices. One of the respondents stated that these children are lucky since included in the project, even if some of the facilities and support from experts are limited. Because, many of the children who didn't get access of inclusion to this project are left behind of education, material support for schooling, food and sheltering shortages which made them join the streets of small and moderate towns of the districts. Hence, I prefer stay here with all the shortcomings than facing street challenges for the orphaned children.

From the view point of this respondent, we can deduce that the project is better preferred than outer conditions which orphaned street children facing in the towns of the country. Many lacks food to eat, clothing, care and support, feeling of parental warmth and even right to live on the streets with all its challenges and poverty. Orphaned children included in the project are kept from harmful assaults on the street, since they are provided advice, materials for schooling and living, sheltering and guidance for future life.

Consequently, as coordinators explained, the orphaned children in the center show unhappy moods and emotions, dissatisfied in the projects activities, longing for relatives and one their family and siblings, inaptness and withdrawal behaviors. These all needs professional counselor as to assist them relieve from the challenges they face than nonprofessional advice in daily communications as indicated by respondents. Another respondent explained that the children in eighth grade feel so bad and seems difficult for project workers to manage since they ask us challenging questions like 'for how long we stay here; what is our fate; who is responsible after graduation; what if we are not successful in schooling; ... which we couldn't answer? Actually, I sympathize their feelings even if I have nothing to bring than giving advice and sharing my experience. This explanation explicitly indicates that there is lack of professional competency to calm challenges the children raise with age difference and maturity. The worry and hesitation put them tactless as to assist the children in their future career and plan of life even though, they share the burden as human beings. The coordinators also are uncertain about future of the orphans in the project than guiding, counseling and directing the children in showing them positive future after completion of their schooling and graduation form the project. Similarly, they 
are doubtful of when to graduate and how to proceed, since there were no written vision, mission and core values documented than oral communications.

\section{Responses of the orphans}

The orphans included in the project appreciate the center for all the supports delivered for them. No one takes care for them, since most of them come from low income and destitute family background. They are giving thank for project founders and coordinators even though they underlined that comparing their life with their counterparts made them less involved. Analysis of interview result from the orphans was identified as of the following:

Fear of each other or fearing of being kicked by other orphans, since they share dormitory with the one who they are not accustomed with

Fear of their caregivers while she/he at times become emotional and aggressive in communicating

Sometimes their caregivers do not comfort them in motherly and fatherly manner Bad feeling about their parental loss, especially when their caregivers not consistently show same characteristics.

The Recreational time is very limited and the belief of confinement in the center.

This result shows that they have still fear towards their roommate after 10 years of living together. They are also uncertain towards their caregivers emotional instability and attachment to children due to either personal characteristics, unsatisfied behavior towards the institution and/mood fluctuation of caregivers. The treatment some caregivers provide for the children also show variance when compared to the motherly relaxation they received before, from their actual mothers. Moreover, the loss of significant family members in life, be defeated when recognizing the children who have intact family in the schools, around their center and surrounding community.

The result obtained from orphan's observation in the center using observational check lists shown that even though many positive behavioral and emotional characteristics observed during short time of observation, there were some adverse characteristics such as anger, verbal abuse to one another, feeling of sadness on few children and lack of involving opposite sex in group playing.

As of the response from interviewed participants regarding challenges they faced in institution, respondents indicated the following major problems. From these, the negative attitude society has towards institutionalization is the leading one., During the start period, few relatives of the orphans $t$ request as to take back the orphans from the institution which disappointed the ones who lost both parents and have no relatives. The other problem was the commitment and support from expected from governmental bodies were challenging ones. The orphans and observation result showed that characteristics of few caregivers and orphans themselves is sometimes challenging for others. Finally, fear of the sustainability of this project due to lack of funding, since the project has contract life of 5 years with the former funding body. 


\section{Discussion}

This chapter presents the discussion of findings in relation to prior studies, and limitations of the study. It is basically intended in visiting, assessing, and describing the basic needs and psychosocial support given to the children at Wolisso Kalehiwot Church orphans rehabilitation center and came up with stating findings of this study. The emphasis given was on the provision of services in terms of basic needs and psychosocial supports for the orphans in regional framework.

Wolisso Kalehiwot Rehabilitation Center is religion based institution established to support children who had lost either or both of their parents due to HIV/AIDS pandemic in the zone. Orphaned children are living and supported by workers in the center, where some of the orphaned children who have/had mothers and relatives may be visited in a given period. In support of this establishment and its purpose, Jayashankar (2012) defined that 'Orphanage is a residential institution devoted to the care of orphans-children whose parents are deceased or otherwise unable to care for them'. Almost all of the orphans provided services in the orphanage secure care and support, since they come from poor/poorest home and streets of the zone (Wolisso). Most of the children were happy about the opportunity when they join the center. Afterwards, with the passage of time and level of maturity they reached upon today, the orphans developed emotional disturbances and instability which made them to be isolated, aggression, bad feeling and mood vacillations. Even though this research undertaking didn't consider underlying causes or difference between different rehabilitation centers, existence of emotional trouble was inevitable. Diverse study done in India comparing institutionalized orphan and non-orphan children, Jayashankar (2012) shown that emotional problems are higher among orphan children in the institution when compared to the non-orphan children. In support to this finding, Chitiyo stated that orphans and the other vulnerable children and adolescents (OVCA) living in institutional homes are more prone to behavioral and emotional problems than others as they are deprived of a family's love and care (Chitiyo et al., 2016).

Tsegaye Chernet (2001) also identified that many problems associated with institutional care and challenged orphan institutions such as inadequate funding to support programs designed for the children, shortage of trained personnel, inadequate skills training that resulted in long care in orphanages, lack of psychosocial services, and lack of long-term strategic planning. In similar context, the result of this study identified correlated problems on the children in the orphanage (Wolisso Kalehiwot Church), where the children often elicit unwanted behaviors among which the following are the central ones: feelings of loneliness and hopelessness, dependency on the adult population for all their needs, and low self-esteem and feeling of inferiority.

Likewise, in the present study the researcher found that characteristics of caregiver in the institution was so difficult to alleviate existing problem of the orphaned children in the institution due to lack of professional skills incompatibility, peculiar behavior of the children, low salary that didn't commensurate with the existing inflation of market in the country and fear of sustainability of the project. In support of this finding, a study done in Europe indicated that orphaned children in an institution needs a surrogate parents in which support is given for small number of orphans by paid adults to feed and care in the center. Browne further narrated about inadequacy of expertise knowledge and 
preparedness that often the staff are inadequately trained and poorly supervised, making basic mistakes such as feeding a child (who should be able feed himself) on his back in a sleeping position (Browne, 2009).

In addition to the poor needs assessment in the selection of orphan children to the institution, inadequate monitoring and evaluation of institutional performance was a challenge as to maintain or envisage on the progress and future of the center/project. This was one of the hectic practices the workers faced as indicated by the two respondents representing the project workers matching with the capacity related problems in provision of caring orphans in rehabilitation center. This finding, augmented by work of Barnett, signifying that 'this is compounded by the lack of training and support of social workers themselves to help them develop alternatives for children. They are often reluctant to place children back with their families or to develop alternative family and community-based care arrangements, because they do not have the skills or adequate support to provide them (Barnett, 2021).

The result obtained from this study, moreover, shown that though many positive behavioral and emotional characteristics observed among orphans in the institution; there were also negative characteristics such as anger, verbal abuse, sadness, and lack of involving opposite sex in group playing. By the same analogy, prior study shown that children who live in the orphanage, unfortunately, suffering from multi-problems. For instance, malnutrition and environmental deprivation of varying degrees are common. Furthermore, orphan children do not receive proper physical and emotional care, because they are unaccompanied, displaced, and lacking family support. If this phenomenon is continued unchecked, it still highly affects the country's development as cited by (Shukla \& Shukla, 2012). In this regard, the author believed that poor handling of the orphan children and the mistrust arising from poor management can lead to different forms of disturbances which need further investigation.

Children assigned to the project develop behavioral problems mainly due to the isolation they faced in the institution and or their aspiration as to notice real family among the surrounding community. Besides, lack of professional competence to handle existing problems of the orphans was another barrier which could aggravate the problem. In support of this finding, Fawzy and Fouad shown that although the basic material needs could be met, orphans in orphanages were almost totally separated from the outside world and could not access normal families and society relations and this would very likely harm their personality in adulthood and social skills (Fawzy \& Fouad, 2007). Finally, the finding in this study identified that there is high skill gap between the institution under study and others, where in the normal circumstance, which assigns counselors and social workers as to address emotional and behavioral problems of children in rehabilitation centers. Availability of trained human power as to assist and being surrogate parent is critical, since the institution is working on developing children who can take responsibility of their own and country in the future career. But, it was recognized that there is huge shortage of skilled human power and professional assignment in the institution. 


\section{Conclusion and recommendations}

\section{Conclusions}

This qualitative study was intended at visiting, assessing, and describing the basic needs and psychosocial support given for children in Wolisso Kalehiwot Church, orphanage center/project. The emphasis was on the provision of services in terms of basic needs and psychosocial supports. As information gathered from project coordinator, church administration, orphans themselves and professional observation of the services, the most commonly identified issues leading to ineffective work performance were, characteristics of caregivers in the institution, characteristics of orphans themselves in the institution, poor monitoring and evaluation of their performance progress and capacity related problems. It is evident that all the efforts made to save life of the orphaned and maintaining wellbeing of these children is blessing effort so far done in the town and the zone. This view was supported by all members of the project, since it opened bread winning center for workers and a paradise for the children with all its limitations.

External challenges the researcher identified as major problems were, negative attitude of the society towards institutionalizing this orphans, especially at initial stage; intrusion of relatives of the orphans to take away the orphans from the institution; failures observed during selection of these orphans; the insufficient commitment and restraint to support this project by governmental bodies were some of the challenging issues. Fear of sustainability of this project owing to lack of external funding bodies to run the program was another foremost challenge for the workers and orphanages in the center, since only about 5 years contractual agreement was left.

The institution is one of the leading rehabilitation centers in the zone and town, where the poor, specifically orphaned children either living with extended family in the route or supported by interested groups or taken from streets of Wolisso and surrounding small towns benefit of the services rendered. The center lost or missed its predestined goal from clients (orphaned children) selection to recruitment of staff members working in the institution. Even though the center has certain drawbacks, it is the shelters that assign surrogate family as to assist the wellbeing and all life needed resources for the children which they never get outside the campus. But, emotional assistance and psychosocial support to be rendered in the center is missing due to the hiring of unskilled and uncertified employee to support children which made life of the orphans in the center more intricate and challenging.

\section{Recommendations}

Based on the results of the study recommendations were drawn. The researcher suggested that it was better if the organization used assessment tools like interview, set of questions that include physical, psychological, and social aspects to identify clearly which orphan must be included in the support system. Even though this institution is on fulfilling the basic needs of these orphans, it lacks technical operations like vision, mission and goals determination which has to be stated clearly as to show its destiny. There is a need for professional counselor/social worker who figure out on physical, psychological and social development of a child and assist in problem solving of these orphans. There is also a need for proper monitoring and evaluation experts as to see whether the 
organizational objectives were/are achieved. The institution must record and document, the activities exercised in the organization for the purpose of performance observation/ evaluation and putting action plan to act on predicted challenges. Finally, the institution is further expected to provide training for assigned social workers and/or caregivers to ensure proper paraprofessional oriented service delivery.

\section{Acknowledgements}

The first and foremost appreciation goes to the elder counselors and Gadaa leaders involved in this study who keenly gave me rewarding information. My grateful appreciation also goes to Jimma University for their financial assistance

\section{Authors' contributions}

Both Authors contributed a lot for the successful completion of the manuscript where the corresponding author plays significant role of supervisory position, and search for journals while the co-author developed proposal, data collection and organization of final draft. Both authors read and approved the final manuscript.

\section{Authors' information}

The corresponding Author, Getachew Abeshu is a Ph.D. holder and Associate professor of counseling psychology at Jimma University, Ethiopia. He has numerous publications on local and International journals on psychosocial support, indigenous counseling and disability areas.

Mr. Dabala Lamessa is a Ph.D. candidate at Addis Ababa University in the area of mental health. His research interest is psychosocial support and has a number of publications in the area.

\section{Funding}

Jimma University is government institution supporting its academic staff conduct community based research that will contribute to nation building, development and change life of the community in its application.

\section{Availability of data and materials}

Data sharing is not applicable to this article as no datasets were generated or analyzed during the current study.

\section{Declarations}

\section{Ethics approval and consent to participate}

Research procedures were strictly followed by securing permission from institution and consent obtaining from respondents. Ethical considerations get due attention since the study was conducted on human beings and community wisdom from research and ethical review board of Education and Behavioral Science College.

\section{Consent for publication}

Jimma University is interested and urging academic staff to publish manuscripts on reputable journals.

\section{Competing interests}

Authors have declared that no competing of interests exists.

\section{Author details}

${ }^{1}$ Department of Psychology, Jimma University, Jimma, Ethiopia. ${ }^{2}$ Department of Psychology, Ambo University, Wolisso CampusWaliso, Ethiopia.

Received: 21 July 2020 Accepted: 8 September 2021

Published online: 30 September 2021

\section{References}

Barett T (2021). What is an orphanage? Wikibuy review: A free tool that saves you time and money Bernard, H. (2002). Research methods in anthropology: Qualitative and quantitative approaches (3rd ed.). Altamira Press. Brink, H. (2009). Fundamentals of research methodology for health care professionals. Juta \& Company. Browne, A. (2009). Developing Language and Literacy. SAGE publications India Pvt.

Burns, N., \& Grove, S. (2009). The practice of nursing research: Appraisal, synthesis and generation of evidence (6th ed.). Saunders Elsevier.

Chitiyo, J., Chityo, A., \& Chityo, M. (2016). Psychosocial Support for Children Orphaned by HIV/AIDS in Zimbabwe. Journal of Childhood Education., 92(6), 465-9.

EDHS - the 2011 Ethiopian Demographic and Health Survey.

Fawzy, N., \& Fouady, A. A. (2007). Prevalence and relationship of religiosity level and suicidal ideation in depressed patients. Egyptian Journal of Psychology, 35(3), 138

Gunderson, J. (2004). Trustworthiness appraisal deficits in borderline personality disorder are associated with prefrontal cortex, not amygdala, impairment. Neurolmage 8(3).

Jayashankar, K. (2012). Racial and ethnic differences in receipt of immediate breast reconstruction surgery: Do hospital characteristics matter? Motilal Banarsidas publishers private limited.

Kaur, R., Vinnakota, A., Panigrahi, S., \& Manasa, R. (2018). A descriptive study on behavioral and emotional problems in orphans and other vulnerable children staying in institutional homes. Indian Journal of Psychological Medicine., 40(2), 161. 
Lewis, J. L., \& Shepherd, S. R. (2006). Culture and communication: Can landscape visualization improve forest management consultation with indigenous communities? Landscape and Urban Planning, 77(5), 291-313.

Myovela B. (2012).The Prevalence of Posttraumatic Stress Disorder and Associated Mental Health Problems among Institutionalized Orphans in Dar es salaam, Tanzania. Journal of clinical child and adolescent psychology.

PEPFAR (2006). An overview of HIV prevention research from the 2006 Implementers Meeting Theo Smart 2 August

Powell, G., et al. (2004). 'Children in residential care: The Zimbabwean Experience', UNICEF \& the Ministry of Public Service, Labour \& Social Welfare. Retrieved August., 24, 2008.

Sendagala S. (2010). Factors affecting the adherence to antiretroviral therapy by HIV positive patients treated in a community based HIV/AIDS care programme in rural Uganda: a case in Tororo district. http://hdl.handle.net/10500/5356

Shukla, B., \& Shukla, D. (2012). Microstructural abnormalities of short-distance white matter tracts in autism spectrum disorder. Neuropsychologia, 49(5), 1378-1382

Susan Rugari, M., Cannon-Diehl, M. R., \& Terri, S. (2012). High-fidelity simulation for continuing education in nurse anesthesia. AANA Journal, 80(3), 191-6.

Streubert, H., \& Carpenter, D. (2007). Qualitative Research in Nursing: Advancing the humanistic imperative. Wolters Kruwel/ Lippincot Williams \& Wilkins.

Thurman, T., Hoffman, A., Chettersi, M., \& Brownell, C. (2007). Triggers of inflammation after renal ischemia/reperfusion. Journal of clinical immunology., 123(1), 7-13.

Tsegaye Cherinet (2001). The Orphanages and its practical application in life changing of children. The Ethiopian journal of Health Development 7(5).

UNICEF (2009). The State of the World's Children. Celebrating 20 Years of the Convention on the Rights of the Child, Brodock Press

UNICEF (2018). Ethiopia: AIDS Orphans live, grow in uncertain future (Annual report)

Zeenat, Y., Charlene, E., \& José, F. (2018). HIV-related stigma and the psychosocial well-being of children orphaned by AIDS: a systematic review. Vulnerable Children and Youth Studies., 13(3), 247-258.

\section{Publisher's Note}

Springer Nature remains neutral with regard to jurisdictional claims in published maps and institutional affiliations.

\section{Submit your manuscript to a SpringerOpen ${ }^{\odot}$ journal and benefit from:}

- Convenient online submission

Rigorous peer review

Open access: articles freely available online

- High visibility within the field

Retaining the copyright to your article

Submit your next manuscript at $\mathbf{s p r i n g e r o p e n . c o m ~}$ 